\title{
SER CUIDADA POR PROFISSIONAIS DA SAÚDE: PERCEPÇÕES E SENTIMENTOS DE MULHERES QUE SOFRERAM ABORTAMENTO ${ }^{1}$
}

\author{
Kellen Daiane Valandro Bazotti², Eniva Miladi Fernandes Stumm ${ }^{3}$, Rosane Maria Kirchner ${ }^{4}$
}

\footnotetext{
${ }^{1}$ Artigo elaborado a partir do Trabalho de Conclusão do Curso (TCC) de Graduação em Enfermagem da Universidade Regional do Noroeste do Estado do Rio Grande do Sul (UNIJUÍ), defendido em 2006.

${ }^{2}$ Enfermeira. Coordenadora do Serviço de Enfermagem da Sociedade Hospitalar Beneficente de Chiapeta. Rio Grande do Sul, Brasil. E-mail: kellendaia@yahoo.com.br

${ }^{3}$ Mestre em Administração. Professor Assistente do Departamento de Ciências da Saúde da UNIJUÍ. Orientadora do TCC. Rio Grande do Sul, Brasil. E-mail: eniva@unijui.edu.br

${ }^{4}$ Doutora em Engenharia Elétrica. Professor Adjunto do Centro de Ciências Rurais de São Gabriel da Universidade Federal de Santa Maria. Rio Grande do Sul, Brasil. E-mail: rosanek@smail.ufsm.br
}

\begin{abstract}
RESUMO: A pesquisa objetiva identificar percepções e sentimentos de mulheres que sofreram abortamento, principalmente relacionados ao cuidado de profissionais da saúde em um hospital. É uma pesquisa qualitativa, exploratória-descritiva. Os instrumentos de coleta de dados foram entrevista aberta e registro em diário de campo. A coleta de dados se deu em dois momentos: durante a internação e nos domicílios. Integraram a pesquisa cinco mulheres que sofreram abortamento espontâneo. Para a análise dos depoimentos utilizou-se a análise temática, emergindo uma categoria: ser cuidada em um hospital: a ótica de mulheres que sofreram abortamento, subdivididas em nove sub-categorias. Vários sentimentos e percepções foram mencionados incluindo medo, nervosismo, tristeza, constrangimento, dor pela perda do filho, satisfação com o atendimento dos profissionais, apoio, segurança, dentre outros. Essa pesquisa pode contribuir com profissionais e estudantes da área da saúde, no sentido de refletir e qualificar a assistência.
\end{abstract}

DESCRITORES: Mulheres. Aborto espontâneo. Emoções.

\section{RECEIVING CARE FROM HEALTH PROFESSIONALS: PERCEPTIONS AND FEELINGS OF WOMEN WHO HAVE UNDERGONE ABORTION}

\begin{abstract}
This study attempts to identify perceptions and feelings of women who have undergone abortions, especially those related to the care of health professionals within a hospital. It is a qualitative and descriptive-exploratory research. The instruments for data collection were an open interview and recording a field diary. Data was collected in two occasions: during hospitalization and in homes. Five women who suffered respective spontaneous abortions were selected for this study. Thematic analysis was used in order to examine their testimonies, with the category to be cared for in a hospital: the perspective of women who have suffered abortion, which then divided into nine categories. Several feelings and perceptions were mentioned, including fear, nervousness, sadness, embarrassment, pain over the loss of the child, satisfaction with the care from health professionals, support, and security, among others. This study may contribute to health care professionals and students, in the sense of reflecting upon and qualifying assistance.
\end{abstract}

DESCRIPTORS: Women. Abortion, spontaneous. Emotions.

\section{SER CUIDADA POR PROFESIONALES DE LA SALUD: PERCEPCIONES Y SENTIMIENTOS DE MUJERES QUE HAN SUFRIDO ABORTO}

RESUMEN: El objetivo de la investigación es identificar las percepciones y sentimientos de mujeres que sufrieron aborto, principalmente, las relacionadas al cuidado de profesionales de la salud en un hospital. Es un estudio cualitativo, exploratorio-descriptivo. Los instrumentos para la recolección de los datos fueron: entrevista abierta y registro en el diario de campo. La recolección de los datos se hizo en dos momentos: durante la internación hospitalaria y en los domicilios. Integraron la investigación cinco mujeres que tuvieron aborto espontáneo. Para el análisis de las declaraciones se utilizó el análisis temático, del cual emergió una categoría: "ser cuidada" en un hospital: la visión de mujeres que abortaron, dividida en nueve subcategorías. Varios sentimientos y percepciones fueron mencionados, incluyendo miedo, nerviosismo, tristeza, vergüenza, dolor por la pérdida del hijo, satisfacción con la atención de los profesionales, apoyo, seguridad, entre otros. Esa investigación puede ser una contribución para los profesionales y estudiantes del área de la salud, en el sentido de permitirles reflexionar y darle calidad a la atención

DESCRIPTORES: Mujeres. Aborto espontáneo. Emociones. 


\section{INTRODUÇÃO}

Mulheres que vivenciam a perda de um filho que está sendo gerado merecem cuidados da equipe de saúde, em especial, da enfermagem. Muitas não esperam este acontecimento, sentindo-se desanimadas, frustradas, tristes, fragilizadas, culpadas, podendo evoluir para depressão. "A culpa, a depressão e a psicossomatização são sinais de feridas psicológicas sofridas pelas mulheres, indicando quão profundamente o aborto às sensibiliza, fazendo-as sofrer física e emocionalmente" 1:220

O abortamento espontâneo é descrito como a expulsão do feto. $\mathrm{O}$ mesmo acontece sem que a mulher esteja esperando, diferente do abortamento induzido, que é realizado com o consentimento da mulher, mas que acarreta danos a ela, gerando, em algumas situações, sentimento de culpa por ter engravidado ou mesmo por ter abortado.

Definem-se como norteadores do cuidado o vínculo e a segurança com a equipe de profissionais que as assistem e "[...] se o profissional possui habilidade de comunicação, terá a capacidade de estabelecer uma relação interpessoal positiva ao interagir com a clientela" . 1:221 Os profissionais estão mais preparados para os procedimentos técnicos do que para a interação com as pacientes. ${ }^{1-2}$

$\mathrm{Na}$ assistência prestada pelos profissionais em um hospital, percebeu-se que o cuidado a estas mulheres não se resumia aos procedimentos técnicos, mas em apoio emocional e interação. Concomitantemente, ocorreram situações constrangedoras, onde o profissional perguntava se o abortamento tinha sido espontâneo ou induzido. Algumas mulheres relutavam em responder, se sentindo, provavelmente, invadidas em sua privacidade, outras aumentando o sentimento de culpa. Neste sentido, a experiência vivida por estas mulheres envolve o sentimento de culpa e/ou medo de ser culpada, experimentados pelo fato de que a sociedade atribui à mulher a função de procriar. ${ }^{3}$

O apoio emocional à mulher se constitui em uma alternativa de aliviar um pouco a sua dor. $\mathrm{O}$ medo do desconhecido, bem como do velho conhecidoé habitual para as pacientes, não interessando quantas vezes já vivenciaram esta situação. Isto envolve também o ser e o estar sendo cuidada, pois a insegurança ou mesmo o medo, refletem na evolução do quadro em que se encontram. ${ }^{4}$

Outra situação presenciada foi de comentários da equipe de enfermagem e médica, relacionados à possíveis razões que levaram a mulher a realizar o abortamento, desconhecendo a história e o contexto vivido por ela. Diante de situações como essas, questiona-se: estaria o profissional no direito de invadir desta forma a privacidade da paciente? Cabia aos mesmos julgar ações dela sem conhecer sua história de vida? E as questões éticas referentes a essas posturas?

Ao profissional que cuida, não cabe opinar ou julgá-las, mas priorizar o bem-estar delas. A maneira de interagir no cuidado é construída a partir de um processo complexo de valorização da sensibilidade e da reciprocidade, por relacionar-se com a vida e o modo de intensificar o relacionamento das pessoas, a fim de que possam se sentir vivendo. ${ }^{5}$

A problemática do abortamento vai sendo vencida e discutida conforme a responsabilidade, o respeito e a confiança entre pacientes e profissionais que atuam nessa área e que se entrelaçam, resultando em assistência qualificada. A participação digna entre as pessoas vai aumentando, à medida que firmam um compromisso de acolhimento. Importante lembrar que o envolvimento de profissionais na assistência provoca enfrentamentos e repercussões nos seus próprios valores e comportamentos relacionados ao tema. ${ }^{6}$

A presente pesquisa objetiva identificar percepções e sentimentos de mulheres que sofreram abortamento, principalmente, relacionados ao cuidado de profissionais em um hospital. Os resultados podem contribuir para o aprimoramento da assistência às mulheres que vivenciam aborto, bem como instigar profissionais e estudantes da área da saúde a refletirem acerca do mesmo e, estimular a produção de mais pesquisas envolvendo essa temática ainda pouco explorada.

\section{PERCURSO METODOLÓGICO}

É um estudo qualitativo, do tipo exploratório descritivo, desenvolvido em um município da região noroeste do Rio Grande do Sul, em outubro de 2006, com cinco mulheres que sofreram abortamento, assistidas em um hospital geral. A definição do número de mulheres integrantes da pesquisa se deu pelo método de exaustão, ${ }^{7} \mathrm{ou}$ seja, a partir do momento em que as informações começaram a se repetir, deu-se por concluída a etapa de coleta de dados.

O primeiro contato com elas ocorreu no hospital e, ao serem convidadas e aceitarem integrar a pesquisa, foram acompanhadas pelas pesquisadoras durante a internação e, posteriormente, foram agendadas visitas nos seus respectivos domicílios, 
em média, uma semana após a alta hospitalar, para então serem realizadas as entrevistas.

Para a coleta de dados utilizou-se entrevista aberta, gravada em áudio-tape e observação em um diário de campo. A entrevista teve como questão norteadora: conte-me, como foi para a senhora (você) ser cuidada pelos profissionais de saúde durante sua permanência no hospital? As observações em campo e as entrevistas foram transcritas e analisadas de acordo com a análise temática. ${ }^{7}$ Da busca de apreender o conteúdo imerso nos depoimentos das mulheres, sujeitos do estudo, emergiu uma categoria, subdividida em nove sub-categorias.

Foram respeitadas as questões éticas que envolvem pesquisas com pessoas, Resolução $\mathrm{N}^{\mathrm{0}} 196 / 96$ do CNS. ${ }^{8}$ Inicialmente o projeto de pesquisa foi registrado no Sistema Nacional de Informação sobre Ética em Pesquisa, concomitantemente, solicitado autorização à Direção do hospital, enviado ao Comitê de Ética em Pesquisa da Universidade Regional do Noroeste do Estado do Rio Grande do Sul, aprovado conforme Parecer Consubstanciado $\mathrm{N}^{\circ} 152 / 2006$. Para as mulheres que aceitaram participar da pesquisa, foi fornecido o Termo de Consentimento Livre e Esclarecido, que foi assinado em duas vias, ficando uma em poder delas e outra das pesquisadoras.

Para manter o anonimato das pesquisadas, optou-se por identificá-las com codinomes de deusas da mitologia grega, pelo fato destas serem mulheres, de gerar filhos e vivenciar a maternidade, sendo que muitas vezes eram criados sonhos e histórias com relação a procriação, o que as tornavam poderosas. Assim, se considera que as mulheres deste estudo, que engravidaram e vivenciaram sentimentos inerentes à maternidade e, concomitantemente, necessitaram elaborar a perda, igualmente são poderosas, pela capacidade de superar momentos de dor que permeiam a perda de um filho. Os codinomes são: Afrodite, Deméter, Ilítia, Hera e Atena.

\section{RESULTADOS E DISCUSSÃO}

Por se tratar de uma investigação qualitativa, considera-se importante uma breve caracterização das mulheres que integraram a mesma. Elas possuíam idade entre 18 e 36 anos; quatro casadas, uma solteira, três não possuíam filhos e duas um e dois filhos. Em relação à profissão, uma era estudante, outra técnica em enfermagem, duas profissionais liberais e uma é dona de casa. Quanto à etiologia do aborto, as cinco mulheres sofreram abortamento espontâneo e foram hospitalizadas e submetidas à curetagem uterina, permanecendo internadas por um dia.

Ao analisar os depoimentos das mulheres que sofreram abortamento, várias percepções e sentimentos emergiram, dentre eles destacamse: satisfação com o atendimento médico e de enfermagem, medo do desconhecido, de estar no hospital pela primeira vez, ansiedade, tristeza, nervosismo, dificuldade de aceitação, sentimento de perda, constrangimento, percepções errôneas em relação ao atendimento vinculado ao plano de saúde, urgência em sair do hospital, local onde ocorreu a perda do filho e, retornar à sua residência. Os mesmos foram agrupados em uma categoria analítica, subdividida em nove subcategorias: atendimento, orientações, ética e privacidade da paciente, perda, ambiência, identidade, plano de saúde, tempo de cuidado e volta para casa.

\section{Ser cuidada em um hospital: a ótica de mu- lheres que sofreram abortamento}

O aborto é um tema polêmico, para o qual se buscam respostas, em especial, para mulheres que realizam abortamento induzido, porém não se pode ignorar as que sofrem abortamento espontâneo e que vivenciam situações diferentes, mas tanto uma quanto a outra possuem sentimentos e percepções merecedores de atenção, de um olhar especial no cuidado por profissionais em um hospital.

\section{$O$ atendimento}

O abortamento desencadeia nas mulheres inúmeros sentimentos e percepções, físicos ou psicológicos, variando com características individuais. "Perceber, contrariando o senso comum, não se constitui apenas no ato de se captar sentimentos subjetivos, mas em receber informações externas e internas ao indivíduo" 9:11 Isso envolve a capacidade dos profissionais saber transmitir informações, pois estas são percebidas e observadas pelas mulheres que sofreram abortamento. Afrodite destaca a atenção e o cuidado da enfermagem, o diálogo, o saber ouvir e o apoio.

Foi tudo bem, ocorreu assim um bom atendimento das enfermeiras, da parte delas principalmente, porque me acalmaram e me ajudaram bastante no momento em que eu fiquei deitada e ansiosa [...], o atendimento foi excelente (Afrodite). 
Em relação ao cuidado, é importante destacar que "[...] os enfoques do cuidado, na sua unanimidade, são centrados na cuidadora, porém o processo de cuidar prevê ações que são desempenhadas em função do ser cuidado" . 10:151

No depoimento de Deméter, ela destaca o atendimento do médico assistente e das técnicas em enfermagem como positivos, já Ilítia não especifica, somente menciona que foi bem atendida por todos.

Eu fui atendida muito bem, desde que eu dei entrada no hospital, o médico me acompanhando, quando eu fui para o bloco cirúrgico [...], as técnicas de enfermagem me receberam, me arrumaram, me levaram para dentro do bloco [...] (Deméter).

[...] todo mundo cuidou bem, todo mundo agiu conforme era para agir, ninguém fez nada errado assim, foi bem (Ilítia).

As ações de cuidado são colocadas em prática no momento em que se transmite ou que se recebe o cuidado. Este é percebido e entendido por meio de comunicação verbal ou não- verbal, incluindo gestos e olhares dentre outros. Qualquer ação humana só é reconhecida quando há valorização do indivíduo em qualquer contexto que se encontre. ${ }^{1}$ Essa forma de atendimento é abordada pelas pesquisadas. Afrodite refere que a comunicação foi importante, ela se sentiu valorizada como ser humano e Atena avalia o cuidado como ausência de palavras grotescas, atitudes que revelem brutalidade, o que não ocorreu com ela.

[...] eu gostei do atendimento, do pessoal, eles me acolheram bem, me acalmaram, a enfermagem me perguntava se estava bem, se precisava de alguma coisa e os médicos também foram legais, conversaram... (Afrodite).

[...] não tenho queixas, ninguém tratou com brutalidade, palavras, alguma coisa ou gestos [...] (Atena).

O fato dos profissionais serem receptivos, acolhedores e comunicativos foi bem aceito por elas, proporcionando-lhes conforto, tranqüilidade e sensação de bem-estar. A mulher, ao perder seu filho, vivencia um momento difícil e esse fato pode desencadear diversas percepções e sentimentos, daí a necessidade de receptividade dos profissionais. Nas observações em campo, nem todos os profissionais foram comunicativos, atenciosos e acolhedores, porém, na ótica das pesquisadas, eles foram.

O enfermeiro possui uma boa capacidade de comunicação interpessoal, consegue definir e perceber se o paciente está sendo atendido em suas necessidades, no entanto, a comunicação interpessoal não inclui somente o aspecto verbal, mas o não-verbal, tal como postura, gestos, tom de voz e olhar entre outros aspectos dessa linguagem. ${ }^{11}$

$\mathrm{O}$ que se percebeu em vários depoimentos foi a maneira dos profissionais de saúde prestarem esse atendimento, destacando-se a comunicação por meio de palavras de conforto, de apoio, estando próximos das pacientes e sabendo ouvir o que elas transmitiam. Proporcionar atendimento humanizado não requer, necessariamente, dedicar mais tempo ao paciente. Basta, para tanto, proferir palavras de conforto, demonstrando segurança e carinho. Dar atenção à pessoa, conversar com ela, deixar que se manifeste e, até, que reclame. ${ }^{11}$

Ao observar os profissionais que atenderam as mulheres, a maioria agiu de forma compatível com as percepções delas, as acompanharam, comunicando-se, desde a internação até a alta hospitalar. Nesse contexto, pessoas que se sentem cuidadas têm maior probabilidade de expressar o cuidado por meio de comportamentos que facilitem o mesmo. ${ }^{12}$

\section{As orientações}

A observação dos profissionais aliada as falas das mulheres, evidencia que o cuidado ocorreu de maneira adequada ao quadro clínico delas. As atitudes dos profissionais no atendimento prestado vão ao encontro das necessidades das mulheres, expressas nos depoimentos: as gurias foram muito legais, conversando, me explicando os procedimentos, o que eu devia fazer, o que podia fazer e o que não podia, então foi muito legal (Hera). [...] eu fui atendida bem [...] pela médica, ela me orientou [...], fui atendida pelos profissionais dali, os enfermeiros, daí eu fiquei na sala de espera, até que veio o médico responsável que iria fazer a curetagem [...] (Atena).

Hera e Atena destacam a importância do diálogo, saber ouvir, responder dúvidas, explicar o que seria realizado, contribuindo para que se sentissem mais calmas, tranqüilas e seguras, porém Atena se reporta aos técnicos de enfermagem e enfermeiros, sem diferenciá-los.

Ao observar a atuação dos profissionais, eles agiram com segurança e calma, procurando compreender o que as pacientes estavam sentindo. No entanto, em algumas ocasiões, evidenciou-se que o médico não se identificava, podendo desencadear constrangimento nas pacientes. Eles iam posicionando-as, organizando o material, para então manter diálogo com elas. Os profissionais 
de enfermagem eram os que mais se preocupavam com o estado emocional das mulheres, os médicos ao contrário, normalmente realizavam os procedimentos de rotina e não observavam as características emocionais, visíveis nessas pacientes que sofreram aborto.

\section{Ética e privacidade da paciente}

Cabe aos médicos e aos profissionais de enfermagem disponibilizar um atendimento às mulheres em abortamento com responsabilidade e ética. A ética que rege as profissões da saúde está presente no processo de cuidar, incluindo respeito aos direitos do ser humano, à vida, à dignidade em todo o ciclo vital, sem discriminação. Falar de aborto é falar de uma questão íntima e pessoal que se refere à feminilidade. As próprias limitações dos seres humanos fazem as pessoas ficarem intimidadas e, quando se está vulnerável, como no caso das mulheres que sofrem abortamento, torna-se mais complexo, principalmente quando são questionadas de forma direta ou indiretamente sobre a etiologia do mesmo.

Me senti invadida na minha intimidade, tinha pessoas que nem sabiam que eu estava grávida [...] aí perguntaram: "como que tu perdeu?" Perdi como era para perder, tu ficava meio sem jeito de responder, pensam que tu fez alguma coisa, que não queria, mas não fiz [...] (Deméter).

Deméter percebeu o sentido do questionamento do médico, não diretamente, mas o suficiente para intimidá-la. Desse modo, se está envolvendo questões éticas e referentes à perda fetal, ao luto e à morte. Contribuindo com o depoimento de Deméter, se presenciou um fato em que o cirurgião questionou a paciente sobre a etiologia do abortamento. A mesma ficou constrangida ao responder a pergunta, afirmando várias vezes que não havia provocado o abortamento, justificando que fora espontaneamente.

O preparo da equipe, além de identificar reações emocionais das mulheres, deve também estar relacionado à maneira de abordá-las. Os questionamentos dos profissionais demonstram se estão agindo com ética ou não. Geralmente, essas mulheres já esperam serem questionadas. Hera reafirma essas considerações ao mencionar que pensou que seria questionada, porém não foi e esse fato a deixou contente: eu achei que iam me perguntar se eu tinha provocado ou coisa assim, ninguém me perguntou nada, nada, nada mesmo, foi muito legal (Hera).
Ao cuidar de pacientes que sofreram abortamento, as ações dos profissionais devem ser pautadas por princípios éticos, pois o que está presente neste acontecimento é outra vida, outro ser humano, um filho que muitas não esperavam perder. No que tange as pesquisadas, três eram primigestas e durante as entrevistas manifestaram sentimentos de frustração, de tristeza e de luto pela perda do filho.

\section{A perda}

O processo de morrer ou a morte estão presentes nas situações de abortamento. Por vezes pensa-se que o aborto não provoca sentimento de perda, por ocorrer no início da gravidez, talvez, por esta razão, os profissionais da saúde tenham dificuldade em lidar com sentimentos/reações emocionais dessas mães. "A nossa experiência com as situações de morte e morrer advém da morte do outro, que nos remete à percepção de que também somos seres para a morte e que, em algum momento de nossa existência, passaremos pelo processo de morrer" ${ }^{13: 52}$

$\mathrm{Na}$ fala de Deméter percebe-se que ela teve dificuldade de aceitar o fato, independente do tratamento dos profissionais. No momento em que fora encaminhada ao centro cirúrgico, estava chorando, inquieta e interrogava os profissionais quanto à possibilidade de engravidar novamente. Ela se sentiu bem atendida, porém o difícil foi lidar com o sentimento de perda: [...] foi tranqüilo em situação com elas, mas nos meus sentimentos estavam [...] bem diferentes, eu não entendia o que estava acontecendo (Deméter).

\section{Ambiência}

Os profissionais podem criar um ambiente tranqüilo, favorável à reflexão sobre o ocorrido, bem como a exteriorização de suas percepções e sentimentos, de maneira que as mulheres não se sintam culpadas e repreendidas, independente da etiologia do abortamento. Para o cuidado não existe tempo nem espaço, inicia antes mesmo da interação entre cuidador e ser cuidado, estendendo-se até após o seu término, produzindo efeitos e mudanças, ciente de que a interação se dá a partir da presença de ambos os envolvidos. ${ }^{10}$

Durante o acompanhamento a estas mulheres, se observou que uma delas, ao entrar no centro cirúrgico com o feto entre as pernas, gerou tumulto na equipe. Não sabiam como proceder, sem agravar o sentimento de perda daquela mãe que chorava desesperada. Percebeu-se que a insegurança dos 
profissionais interferiu na abordagem à paciente. A atitude da enfermagem repercutiu nas reações da paciente, exacerbando o medo e a insegurança dela. Nesse contexto, a atenção à mulher vai além de procedimentos técnicos. Ela deve ser informada a respeito de tudo o que irá ser realizado, com clareza, seriedade, favorecendo uma relação de confiança. Hera destaca a forma de atendimento do anestesista, que lhe transmitiu segurança e Deméter destaca a atenção do anestesista e da enfermeira.

$O$ anestesista foi muito gentil comigo, me explicou o que eu ia sentir, perguntou se eu já havia tomado anestesia [...], me chamou pelo nome, foi muito gentil, me deixou tranqüila... (Hera).

$O$ anestesista o tempo todo esteve presente, me acalmando, falando tudo que ia fazer, que eu não ia sentir nada, não ia sentir dor. A enfermeira me puncionou, falava o que ia fazer, foi tranqüilo [...] (Deméter).

\section{Identidade}

Em alguns momentos foram presenciadas situações em que o médico se referiu à paciente pelo procedimento a ser realizado curetagem e não pelo seu nome. Essa postura pode gerar constrangimento na paciente, descaso e desvalorização, demonstrando falta de ética e compromisso com a pessoa sob seus cuidados. Os médicos no exercício profissional possuem responsabilidades éticas, que devem ser cumpridas, para que não ocorram infrações éticas no desempenho de suas funções. ${ }^{14}$ Conflitos éticos são problemas de saúde que persistem e envolvem as relações humanas. ${ }^{15}$ Contrariando o exposto, Hera se sentiu bem cuidada e o fato de ser chamada pelo nome contribuiu.

Ao anestesista compete questionar as pacientes sobre sua história, o uso de medicamentos, doenças atuais e anteriores, antecedentes familiares, entre outros, antes de administrar a anestesia. Ilítia manifesta que foi bem cuidada, enfatizando a comunicação não verbal, mais especificamente, o olhar. A comunicação se dá por meio do olhar, da postura e da expressão facial, tendo por objetivo acalmar, aliviar e confortar as pessoas, não somente utilizando a técnica da linguagem por meio de palavras, pois o conforto também é oferecido com outras maneiras de comunicar. ${ }^{16}$

Eu pude ver que cada vez que eu ia me informar, perguntar alguma coisa [...] se ia doer, se não ia [...] todos me respondam com calma, olhando para mim... (Ilítia).

Oportuno destacar que quando os profissionais desenvolvem seu trabalho com qualidade, as pacientes sentem-se à vontade para expor seus sentimentos. "Se a comunicação entre o enfermeiro e o paciente não ocorrer efetivamente, o significado do cuidado que prestamos pode ser afetado profundamente" 9:69

\section{Plano de saúde}

A atenção dos profissionais da saúde deve ser igual para todos os pacientes, independente do plano de saúde que possuem. Nas observações em campo, evidenciou-se que isto não ocorria com todos os pacientes, principalmente com usuários do Sistema Único de Saúde (SUS).

Quando eu vim para casa eu comentei, me senti segura, importante... quando uma pessoa vai para uma casa de saúde e ela não é bem tratada, ela se sente mal, deve se sentir assim um lixo, principalmente quando se fala de SUS, de coisa assim [...] (Hera).

Eu não tenho plano de saúde, assim eu gostei mais da sala de recuperação que lá debaixo, porque ali na emergência [...] é sempre meio corrido, o pessoal não pode ficar sempre ao redor da gente, só quando a gente chama, porque são muitas pessoas entrando e saindo no hospital ali (Atena).

Constata-se que a população, em muitas situações, possui percepções errôneas relacionadas ao SUS. Hera demonstra isso ao enfatizar que se sentiu importante por ser tratada como se tivesse um plano de saúde privado: eu não tenho convênio nenhum e fui tratada como uma pessoa que tivesse. Me senti importante, assim, quando o médico foi lá na observação conversar comigo, me explicar o horário que iam me levar pro bloco cirúrgico, qual o procedimento que ia ser feito [...] (Hera).

\section{O tempo do cuidado}

A administração do tempo no cuidado prestado e a maneira dos profissionais abordarem as mulheres ao chegarem ao hospital, são mencionadas pelas pesquisadas. A permanência prolongada no hospital e a primeira vez em que são internadas podem gerar inquietude e desconforto. O tempo de permanência do paciente em um hospital varia de acordo com a especialidade e o tipo de atendimento. ${ }^{17}$

A única coisa que eu achei é que eu tive que esperar quase um dia ali, achei demorado pra liberar a sala de cirurgia (Atena).

[...] eu estava louca para ir embora, tu quer sair dali, esquecer o que passou, está meio deprimida, uma coisa que tu não esperava [...] eu não me sentia bem comigo mesma [...] (Deméter). 
Atena menciona que a espera pelo atendimento deixou a desejar e Deméter demonstra tristeza e sentimento de perda, principalmente quando menciona que queria voltar para casa, tentar esquecer o fato. Para ela o aborto foi inesperado e a deixou triste. As mulheres revelam que percebem esse tempo de hospitalização como longo, que demora a passar. O tempo de internação até a curetagem e, posteriormente, até a alta é esperado com muita ansiedade pela maioria das mulheres, apesar do tempo médio de internação. ${ }^{18}$

Atena se reporta também à sua permanência no hospital: tem muitas pessoas que ficam lá, como eu, da manhã até o final da tarde, na sala de espera, antes de ir para a sala de cirurgia, a gente observa tanta coisa [...] tinha outras pessoas comigo ali também esperando, mas tem que esperar, fazer o que? (Atena).

Ao analisar o depoimento de Atena, ao mesmo tempo em que ela se sente prejudicada pela espera, tenta entender o motivo da demora no atendimento, compreendendo que outras pessoas, igualmente, necessitam de cuidados.

\section{De volta para casa}

A permanência no hospital normalmente é vista como algo negativo e que quando extrapola o período de internação, as mulheres ficam ansiosas, se preocupam e muitas vezes desejam voltar ao seu cotidiano. Hera reforça suas percepções e sentimentos ao falar do tempo de internação: eu estava apreensiva no pós, para sair lá de dentro, fiquei nervosa em razão da minha mãe estar sozinha em casa e não saber o que estava acontecendo comigo lá [...] (Hera).

Hera sentiu necessidade de sair do ambiente onde ocorreu a perda, desviando sua atenção para a preocupação com seus familiares. As pacientes sentem desejo de retornar para casa e nesse retorno têm a esperança de esquecer o que ocorreu no período de internação. ${ }^{18}$

Ilítia menciona que se sentiu nervosa, principalmente pelo fato de estar no hospital pela primeira vez e por não ter conhecimento do que iria acontecer com ela, no entanto relata que o bom atendimento a fez sentir-se melhor: fiquei bastante nervosa, porque eu nunca tinha ido para um hospital, nervosa assim, mas depois deu tudo certo [...] (Ilítia).

Ao acompanhar Ilítia ela estava ansiosa, trêmula, insegura e chorando intensamente. Nesse contexto, a internação em uma unidade hospitalar significa uma ameaça à vida e ao bem-estar daqueles que são admitidos e que passam por novas vivências. ${ }^{19}$
Analisando os conteúdos dos depoimentos das mulheres, sujeitos do estudo, aliados aos posicionamentos dos autores e as observações registradas em diário de campo, várias percepções e sentimentos emergiram, tanto relacionados à atenção, ao cuidado pelos profissionais da saúde, quanto ao fato de perderem seus filhos.

O processo de abortamento e a hospitalização das mulheres pesquisadas se constituem em momento difícil, no qual se sentem frágeis, tristes, ansiosas pela perda do bebê, necessitando de apoio e cuidados especiais da equipe de profissionais que as assistem.

\section{CONSIDERAÇÕES FINAIS}

Esse estudo oportunizou estar próximo às mulheres pesquisadas, observar suas reações, percepções e sentimentos. Desse modo, o objetivo traçado foi alcançado. Buscou-se apreender o explícito e o implícito no conteúdo dos depoimentos, proporcionando momentos de trocas, as quais foram produtivas e ajudaram a compreender a forma como elas vivenciaram o cuidado de profissionais da saúde em um hospital.

As mulheres percebem o atendimento dos profissionais como adequado às suas necessidades, desde a admissão até a alta e a satisfação é manifestada em seus depoimentos, o que contribuiu para sentirem-se acolhidas e seguras. Elas perceberam diversas maneiras de cuidar, incluindo a não verbal.

Em relação aos sentimentos vivenciados pelas mulheres pesquisadas, destacam-se: tristeza, dor pela perda, angústia, medo, ansiedade, nervosismo e constrangimento. Durante a hospitalização elas salientaram que a comunicação e o saber ouvir são fundamentais no cuidado e na relação paciente-profissional.

Evidencia-se também a satisfação das pesquisadas com o atendimento dispensado pelos profissionais, amenizando o sofrimento pela perda de seus filhos. Elas se sentiram valorizadas quanto à atenção prestada pelos profissionais, além do esperado. Chama atenção o fato de elas se surpreenderem com a qualidade do atendimento, principalmente por serem usuárias do SUS. Essa percepção é errônea, pois independente do plano de saúde que a pessoa possui, tem direito a uma assistência digna e qualificada.

A interrupção da gravidez foi percebida pelas mulheres como um momento difícil, no qual se sentiram fragilizadas, tristes e frustradas, 
porém a maioria dos profissionais agiu de forma adequada, respeitando, proporcionado apoio, informações precisas, palavras de conforto e, acima de tudo, souberam ouvir e, dessa forma, qualificaram a assistência.

Considera-se importante a realização de mais estudos envolvendo essa temática, inclusive com novos olhares. O fato de realizar essa pesquisa fora do ambiente hospitalar foi positivo, denotando respeito ao sofrimento das pesquisadas e, principalmente, qualificando as informações obtidas. Elas, em suas residências, se sentiram à vontade, sem medo ou constrangimento de falar sobre suas percepções e sentimentos relacionados ao cuidado dos profissionais no hospital.

A relevância dessa pesquisa centra-se na possibilidade de despertar nos profissionais da saúde e estudantes em formação, reflexões sobre o cuidado, que vão além do conhecimento científico e de procedimentos técnicos, envolvendo percepções, sentimentos, ética, dentre outros. No que tange, especificamente, à equipe de enfermagem, os resultados dessa investigação podem ampliar conhecimentos e favorecer o cuidado, por meio de um planejamento adequado, incluindo a sistematização da assistência de enfermagem.

Construir essa pesquisa se constituiu em um grande desafio, pois a abordagem de um tema polêmico como o abortamento suscitou várias inquietações, principalmente relacionadas à aceitação das mulheres em integrarem a população estudada, aliadas ao acompanhamento das pesquisadoras durante a permanência delas no ambiente hospitalar.

\section{REFERÊNCIAS}

1. Motta IS. A relação interpessoal entre profissionais de saúde e a mulher em abortamento incompleto: "o olhar da mulher". Rev Bras Saude Mater Infant. 2005 Abr-Jun; 5(2):219-28.

2. Mariutti MG, Almeida AM, Panobianco MS. O cuidado de enfermagem na visão de mulheres em situação de abortamento. Rev Latino-am Enfermagem. 2007 Jan-Fev; 15(1):20-6.

3. Kaminski MM. A vivência de mulheres no processo de perda em virtude de abortamento [monografia]. Ijuí (RJ): Universidade Regional do Noroeste do Estado do Rio Grande do Sul; 2004.
4. Scortegagna LS. Conhecendo as percepções das puérperas e da equipe de enfermagem no processo de parto. [monografia]. Ijuí (RJ): Universidade Regional do Noroeste do Estado do Rio Grande do Sul; 2002.

5. Bettinelli LA. Cuidado Solidário. Passo Fundo (RS): Berthier; 1998.

6. Soares GS. Profissionais de saúde frente ao aborto legal no Brasil: desafios, conflitos e significados. Cad Saúde Pública, 2003 Mar-Abr; 19(2):399-406.

7. Minayo MCS, organizador. Pesquisa social: teoria, método e criatividade. Petrópolis (RJ): Vozes; 2002.

8. Ministério da Saúde (BR), Conselho Nacional de Saúde, Comitê Nacional de Ética em Pesquisa em Seres Humanos. Resolução No 196 de 10 de outubro de 1996: diretrizes e normas regulamentadoras de pesquisa envolvendo seres humanos. Brasília (BR): MS; 1996.

9. Cianciarullo TI. Instrumentos básicos para o cuidar: um desafio para a qualidade de assistência. São Paulo (SP): Atheneu; 2005.

10. Waldow VR. Cuidado humano: o resgate necessário. $3^{\mathrm{a}}$ ed. Porto Alegre (RS): Sagra Luzzato; 2001.

11. Silva MJP, organizador. Qual o tempo do cuidado? Humanizando os cuidados de enfermagem. São Paulo (SP): Edições Loyola; 2004.

12. Waldow VR. Estratégias de ensino na enfermagem: enfoque no cuidado e no pensamento crítico. Petrópolis (RJ): Vozes; 2005.

13. Souza LGA, Boemer MR. O cuidar em situação de morte: algumas reflexões. In: Simpósio: Morte: Valores e Dimensões. Ribeirão Preto (SP): USP; 2005.

14. Boyaciyan K, Camano L. O perfil dos médicos denunciados que exercem ginecologia e obstetrícia no estado de São Paulo. Rev Ass Med Brasil. 2006 Maio-Jun; 52(3):144-7.

15. Zoboli ELCP, Fortes PAC. Bioética e atenção básica: um perfil dos problemas éticos vividos por enfermeiros e médicos do programa saúde da família, São Paulo, Brasil. Cad Saúde Pública. 2004 Nov-Dez; 20(6):1690-9.

16. Waldow VR. Cuidado humano: o resgate necessário. $2^{\mathrm{a}}$ ed. Porto Alegre (RS): Sagra Luzzatto; 1999.

17. Jacobs PC, Matos EP. Estudo exploratório dos atendimentos em unidade de emergência em Salvador-Bahia. Rev Ass Med Brasil. 2005 Nov-Dez; 51(6):348-53.

18. Boemer MR, Mariutti MG. A mulher em situação de abortamento: um enfoque existencial. Rev Esc Enferm USP. 2003 Nov; 37(2):59-71.

19. Hudak CM, Gallo BM. Cuidados intensivos de enfermagem: uma abordagem holística. $6^{\mathrm{a}}$ ed. Rio de Janeiro (RJ): Guanabara Koogan; 1997. 